\title{
A TRANSGRESSÃO EM BERNARDO GUIMARÃES
}

\section{TRANSGRESSION IN BERNARDO GUIMARÃES}

Norberto PERKOSKI ${ }^{1}$

RESUMO: Neste artigo, são analisados três poemas de Bernardo Guimarães: "A orgia dos duendes", "Elixir do pajé" e "A origem do mêstruo". O referencial teórico-crítico embasase em Mikhail Bakhtin, Georges Bataille, Antonio Candido, Haroldo de Campos, Luiz Costa Lima e Duda Machado. No primeiro dos poemas, subverte-se o tema romântico do espaço acolhedor; no segundo, questiona-se a virilidade masculina e, no último, através da invenção, dessacraliza-se a mitologia clássica. Predomina na construção dos textos uma linguagem transgressora que, via intertextualidade, invade o cânone literário, engendrando um correlato riso subversivo. Através dessas obras, Bernardo Guimarães institui-se como desordenador do idealismo predominante e já desgastado da primeira geração romântica do sistema literário brasileiro. PALAVRAS-CHAVE: Poesia brasileira. Bernardo Guimarães. Invasão do cânone.

ABSTRACT: In this article were analyzed three poems by Bernardo Guimarães: "A orgia dos duendes", "Elixir do pajé" and "A origem do mênstruo". The theoretical and critical reference is based on Mikhail Bakhtin, Georges Bataille, Antonio Candido, Haroldo de Campos, Luiz Costa Lima, and Duda Machado. In the first poem, the romantic theme

${ }^{1}$ Professor da Graduação e do Mestrado em Letras da Universidade de Santa Cruz do Sul (UNISC), CEP 96815-900, Santa Cruz do Sul, RS, Brasil, perkoski@unisc.br 
is subverted from the friendly environment; in the second poem, the male virility is questioned; and in the last one, through invention, the classical mythology is desacralized. A transgressive language prevails in the construction of the texts, which, through intertextuality, invades the literary canon, engendering a correlate subversive laughter. Through these works, Bernardo Guimarães is established as the disturber of the prevailing and already worn idealism of the first romantic generation of the Brazilian literary system.

KEYWORDS: Brazilian poetry. Bernardo Guimarães. Canon Invasion.

De início, saliente-se que, segundo Duda Machado (1992), as poesias "completas" de Bernardo Guimarães, publicadas pelo Instituto Nacional do Livro, em 1959, sofreram a ação da censura no que se refere à omissão de dois dos seus poemas eróticos, "Elixir do pajé" e "A origem do mênstruo". Foram retirados do ostracismo a que haviam sido relegados por duas novas edições: a de Sebastião Antunes, em 1988, em tiragem limitada, pela Dubolso, com "Introdução" de Romério Rômulo, e a organizada pelo citado Duda Machado, pela Imago, em 1992.

No prefácio dessa última, Duda Machado (1992), no ensaio esclarecedor denominado "Sátira e humor à margem do Romantismo", ressalta a guinada que ocorreu recentemente com a fortuna crítica da obra de Bernardo Guimarães, empreendida primeiramente por Haroldo de Campos e seguida, entre outros, por Luiz Costa Lima e, acrescente-se, pelo próprio autor do prefácio.

Haroldo de Campos, em oposição a uma poética diacrônica, que não se preocupa em hierarquizar as produções literárias do passado "de um ponto de vista estético atual" (1977, p.205), valoriza a reavaliação sincrônica, "cuja função tem um caráter eminentemente crítico e retificador sobre as coisas julgadas da poética histórica" (1977, p.207). Propõe, embasado por essa conceituação, uma Antologia da Poesia Brasileira de Invenção: 
onde os autores selecionados da fase colonial ao Modernismo, o fossem por uma contribuição definida para a renovação de formas em nossa poesia, para a ampliação e a diversificação de nosso repertório de informação estética.(CAMPOS, 1977, p. 208-209)

A partir desse ponto de vista, considera a produção poética de Bernardo Guimarães bem mais importante do que a sua prosa, tachando-o, nesse passo, como "romancista medíocre":

O que nos interessa hoje de seu acervo é a parte burlesca, satírica, de "bestialógico" e "non sense", de seu estro poético. Neste sentido, um precursor brasileiro do surrealismo. [...] A poesia erótico-escatológica de Bernardo, como também, antes, a de Gregório, deve ser objeto de reexame, sem falsos pudores ou pruridos cediços. (CAMPOS, 1977, p. 211-212)

Como acima já se mencionou, prosseguindo na esteira aberta por Haroldo de Campos, críticos recentes retomaram a obra de Bernardo Guimarães sob um novo viés avaliativo. Entre eles, Luiz Costa Lima (1991) que, no ensaio "Bernardo Guimarães e o cânone", distingue entre o "Bernardo legitimado e o excluído" (p.243-244) da fortuna crítica brasileira. 0 que aqui interessa é o segundo, no qual, segundo o crítico, "predomina a paródia, o humor, quando não a agressão declarada aos modelos vigentes" (p.245). É o que se pretende agora analisar através de seus poemas eróticos "A orgia dos duendes", "Elixir do pajé" e "A origem do mênstruo", que se constituem, entre outros poemas do autor, como transgressores do cânone instituído.

\section{"A orgia dos duendes"}

"A orgia dos duendes" faz parte da obra Poesias, cujo lançamento data de 1865. Estruturado em cinco partes, numeradas, o poema apresenta-se regular quanto aos seus aspectos formais: as estrofes são constituídas de quartetos eneassílabos, com acentos rítmicos 
na terceira, sexta e nona sílabas. 0 esquema rímico é $A B A B$, com predominância de rimas pobres.

$\mathrm{Na}$ primeira parte, quando soa a meia-noite, começa a preparação "para a ceia da grande folia"2 em que participam animais personificados ou míticos, vinculados ao universo brasileiro: enquanto Lobisome acende a fogueira no chão, Taturana, uma espécie de lagarta urticante, frita na panela "um menino com tripas e tudo" (p. 17), Getirana, inseto de grande porte, acrescenta um morcego "que ali mesmo co'as unhas sangrava" (p. 17) e Mamangava, tipo de abelha, frige com a banha extraída do cachaço de um frade, acompanhado de pernas de aranha, "fresco lombo de um frei dom abade" (p. 17).

A velhinha, rainha da festa, convoca, então, ao batuque várias figuras, entre elas, as filhas do oco do pau, o Esqueleto, o Galo-preto, o Sapo-inchado, o Crocodilo, o Lobisome e as:

Raparigas do monte das cobras,

Que fazeis lá no fundo da brenha?

Do sepulcro trazei-me as abobras,

E do inferno os meus feixes de lenha. (p. 17)

No início da segunda parte, comparecem outras figuras:

Mil duendes dos antros saíram Batucando e batendo matracas, E mil bruxas uivando surgiram, Cavalgando em compridas estacas. (p. 18)

No batuque, há a participação de um diabo tocando campainha com uma caveira, enquanto outros "agitam sonoros chocalhos" (p.18). Crocodilo ronca com o papo, Esqueleto toca tambor na

\footnotetext{
${ }^{2}$ GUIMARÃES, Bernardo. Elixir do pajé: A origem do mênstruo, A orgia dos duendes. Sabará (MG): Dubolso, 1988. p.17. Todas as outras citações foram extraídas dessa edição, sendo indicado, entre parênteses, o número da página correspondente. Cumpre esclarecer que este artigo teve por base um dos capítulos de nossa tese de doutorado "A escritura erótica no sistema literário brasileiro", defendida em 1996, na PUCRS.
} 
barriga inchada de um sapo, Lobisome bate a batuta e Getirana arranha uma guitarra. A última estrofe é uma introdução da terceira parte, em que se farão presentes as vozes dos participantes:

\author{
E dançando em redor da fogueira \\ vão girando, girando sem fim; \\ Cada qual uma estrofe agoureira \\ Vão cantando alternados assim: (p. 18)
}

Dessa forma, vários daqueles que integram o batuque enunciam o seu discurso, revelando o que eram antes de sofrerem o processo de metamorfose. Nesse passo, os grandes criticados por Bernardo Guimarães são a nobreza, a aristocracia e, principalmente, a Igreja, tanto individualmente quanto como instituição. Diversos partícipes foram importantes figuras relacionadas ao clero: Taturana, uma freira; Galo-preto, um frade; Esqueleto, um inquisidor; Crocodilo, papa. 0 Lobisome, por seu turno, foi rei e afirma:

Do meu reino e de minhas cidades

0 talento e a virtude enxotei;

De michelas, carrascos e frades

De meu trono os degraus rodeei. (p. 19)

Cada um relaciona os crimes cometidos, causa de sua danação atual: incesto, assassinatos, aborto, luxúria, antropofagia... Confiram-se algumas vozes, predominantemente associadas a transgressões de cunho erótico:

\title{
TATURANA
}

Dos prazeres de amor as primícias,

De meu pai entre os braços gozei;

E de amor as extremas delícias

Deu-me um filho, que dele gerei. (p. 18) 
GETIRANA

Por conselhos de um cônego abade

Dous maridos na cova soquei;

E depois por amores de um frade

Ao suplício o abade arrastei. (p. 18)

\section{GALO-PRETO}

Como frade de um santo convento

Este gordo toutiço criei;

E de lindas donzelas um cento

No altar da luxúria imolei. (p. 19)

\section{CROCODILO}

De princesas cruéis e devassas

Fui na terra constante patrono;

Por gozar de seus mimos e graças

Opiei aos maridos sem sono. (p. 19)

Por fim, ouve-se a voz da Rainha, que a todos ultrapassa na prática de horrores: mata a mãe ao nascer, esgana o pai, atira um irmão no fundo de um poço, liquida também os seus três maridos e todos os amantes. Cônscia de seu poderio, enfatiza:

Quem pratica proezas tamanhas

Cá não veio por fraca e mesquinha,

E merece por suas façanhas

Inda mesmo entre vós ser rainha. (p. 20)

Na primeira estrofe da quarta parte, o batuque chega ao seu ápice e, igualmente, Bernardo Guimarães alcança um dos seus melhores momentos de imitação, via melopeia, através do emprego da vogal "i", trabalhada como a tônica final dos quatro versos que integram a estrofe, sugerindo o frenesi da dança que atinge o seu clímax no terceiro verso pelas repetições e pelo uso do vocábulo "veloz", que se associam à rapidez dos movimentos: 
Do batuque infernal, que não finda,

Turbilhona o fatal rodopio;

Mais veloz, mais veloz, mais ainda

Ferve a dança como um corrupio. (p. 20)

No entanto, a segunda estrofe instaura a ruptura e o término do batuque: ouve-se o estalo de um rebenque e surge "um magro espectro sinistro" (p. 20), que, na estrofe seguinte, se revela:

Hediondo esqueleto aos arrancos

Chocalhava nas abas da sela;

Era a Morte que vinha de tranco

Amontada numa égua amarela. (p. 20)

A Morte também enuncia o seu discurso e acaba com a farra, obrigando seus participantes a voltarem ao seu espaço apropriado, isto é, ao inferno:

"Fora, fora! esqueletos poentos,
Lobisomes, e bruxas mirradas!
Para a cova esses ossos nojentos!
Para o inferno essas almas danadas!"
Um estouro rebenta nas selvas,
Que recendem com cheiro de enxofre;
E na terra por baixo das relvas
Toda a súcia sumiu-se de chofre. (p. 20)

Na quinta e última parte, com a chegada do dia, não sobra nenhum vestígio do dionisíaco da noite anterior, e o poema encerra com o aparente retorno da ordem natural:

E na sombra daquele arvoredo,

Que inda há pouco viu tantos horrores,

Passeando sozinha e sem medo

Linda virgem cismava de amores. (p. 20)

Antonio Candido já se referiu ao poema como um dos fulcros do satanismo brasileiro em que ocorre, entre outros aspectos, "o 
sadismo certamente mais cruel da nossa poesia" (1975, p.176), escamoteado pelo uso do humor:

0 tom de galhofa e o disfarce do estilo grotesco acobertaram (quem sabe para o próprio autor), dandolhe viabilidade em face da opinião pública e do sentimento individual, uma nítida manifestação de diabolismo; luxúria desenfreada e pecaminosa, gosto pelos contrastes profanadores, volúpia do mal e do pecado. (CANDIDO, 1975, p. 177)

Haroldo de Campos, por seu turno, apontou como um dos traços caracterizadores do poema o "pandemônio fáustico em ritmo de arremedo gonçalvino" (1977, p. 211). Duda Machado acrescenta que "em relação à paródia, Basílio de Magalhães, biógrafo e comentador da obra de Bernardo, vai direto ao ponto: $O$ Canto do Piaga de Gonçalves Dias" (1992, p. 12). 0 crítico vai mais longe e, embasado em Mikhail Bakhtin, associa características do realismo grotesco rabelaisiano ao trabalho poético que ocorre em "A orgia dos duendes" e enfatiza:

Horror e humor convivem de perto, criando uma interpenetração e ambivalência que domina todo o poema; a orgia com seu aspecto demoníaco por lentes carnavalizadas. (MACHADO, 1992, p.13)

Quanto à análise da última parte, Duda Machado, de maneira perspicaz, opõe-se à interpretação redutora que a considera tãosomente "como uma espécie de amenização ou apaziguamento face à transgressão aos modelos da época", preferindo salientar que "este trecho mantém o caráter de ambivalência que rege $A$ Orgia dos Duendes e nega afirmando" (1992, p.14). Argumenta o crítico:

Não há nada semelhante a uma retratação; a natureza pacificada e idílica que enquadra e acolhe um outro clichê do nosso romantismo, o culto às virgens [...], está repassada por uma clara ironia, já que o lugar só 
parece ser ameno ou idílico porque se ignora sua outra dimensão... (MACHAD0,1992, p.14-15)

Avança, ainda, salientando que o final de "A orgia dos duendes" pode ser lido como a "subversão do tema romântico da natureza sublime ou espiritualmente acolhedora” (1992, p.15). Já quanto à totalidade do poema, considera-o também como "libertação dos mitos românticos da natureza e, ao mesmo tempo, como desmascaramento carnavalizado da poética do 'sentimento noturno' e do satanismo" (1992, p.15). E, por fim, como:

uma réplica magnífica em termos de humor crítico aos emblemas ingênuos de brasileirismo e às idealizações adocicadas tão frequentes em nosso romantismo. (MACHAD0,1992, p.15)

No entanto, há que se salientar também que, quanto à escritura erótica, o texto de Bernardo Guimarães move-se em uma tensão: conquanto transgrida pelo descomedimento, no que se refere à eleição do assunto focalizado, o vocabulário, contudo, mantém-se predominantemente dentro do cânone moral aceitável da época. Daí por que foi possível publicá-lo no século XIX. 0 rompimento total no que tange à escritura erótica só ocorreria nos poemas de edição limitada e clandestina, o que se poderá constatar a seguir.

\section{"Elixir do pajé"}

Bernardo Guimarães lança, em 1875, mesmo ano da publicação de A escrava Isaura, os seus dois poemas tachados de obscenos. A obra trazia como título, conservado até hoje, apenas Elixir do pajé, omitindo - o que será discutido mais adiante - o nome de "A origem do mênstruo", o outro poema que também integrava a obra.

Em 1958, Elixir do pajé teve "edição reduzida e com exemplares numerados”, (BRANCO, 1987, p.64), antes já se disseminara em várias outras edições clandestinas, tornando-se o poema-título 
extremamente popular, pois, consoante acentua Artur Azevedo, "é raro o mineiro que não o saiba de cor" (MACHADO, 1992, p.16). A declaração, conquanto exagerada, revela, não só o processo básico de circulação do poema, a oralidade, mas também um aspecto fundamental do erótico: por mais "obscena", aqui no sentido de "fora de cena", que seja considerada uma criação, ela provoca a sua inserção no processo cultural, abrindo caminhos outros que não os marcados pela veiculação convencional. Dito de outra forma: o próprio processo de circulação eleva-se à condição de estatuto transgressor.

De estrofação livre, o poema contém esquemas rímicos também variados. Quanto à métrica, ocorrem em maior número versos pentassílabos, heptassílabos e decassílabos. Em menor escala, aparecem os hexassílabos. Dos três poemas aqui focalizados, é o que apresenta maior liberdade formal.

Pode-se dividir a estrutura do poema "Elixir do pajé" em três momentos. 0 primeiro deles inicia com uma apóstrofe do eu lírico ao membro impotente, retratando, por extensão, o estado psicológico do seu possuidor. Tristeza, pesar e melancolia são os sentimentos predominantes, contrapostos à saudade da virilidade plena, situada no passado:

Que tens, caralho, que pesar te oprime que assim te vejo murcho e cabisbaixo, sumido entre essa basta pentelheira, mole, caindo pela perna abaixo?

Nessa postura merencória e triste para trás tanto vergas o focinho, que eu cuido vais beijar, lá no traseiro, teu sórdido vizinho!

Que é feito desses tempos gloriosos em que erguias as guelras inflamadas, na barriga me dando de contínuo tremendas cabeçadas? (p. 25) 
Nos "tempos gloriosos", o membro, pleno de energia, é comparado a uma "hidra furiosa" (p. 25) que, "faminto e arquejante" (p. 25), pedia um "cabaço" (p. 25), considerado como "única empresa digna" (p. 26) de sua exigência.

0 eu-lírico prossegue, questionando-se quanto à possível causa originária de sua situação atual. Uma blenorragia: "Acaso pra teu tormento,/ indefluxou-te algum esquentamento?" (p. 26). A violência de uma masturbação mais afoita: "Porventura do tempo a dextra [sic] irada/ quebrou-te as forças, envergou-te o colo," (p. 26). Retoma, então, as avaliações acerca de um membro impotente e, além de considerá-lo como "inútil lâmpada apagada/ entre duas colunas penduradas" (p. 26), acrescenta:
Caralho sem tesão é fruta chocha, sem gosto nem cherume linguiça com bolor, banana podre, é lampião sem lume, teta que não dá leite, balão sem gás, candeia sem azeite. (p. 27)

Entretanto, a primeira parte é concluída por uma guinada esperançosa, pois o problema pode ser resolvido. 0 tom da apóstrofe é redirecionado para uma nova possibilidade de tesão, em que não está ausente a comparação com o deus romano Marte, o Ares dos gregos, conhecido pelo grande número de aventuras amorosas. Tudo isso, graças a um "elixir miraculoso":

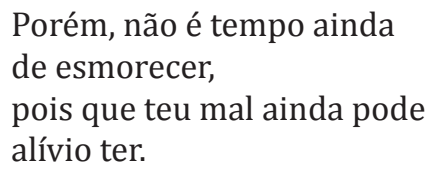

Sus, ó caralho meu, não desanimes, que inda novos combates e vitórias e mil brilhantes glórias a ti reserva o fornicante Marte, que tudo vencer pode co'engenho e arte. 
Eis um santo elixir miraculoso, que vem de longes terras, transpondo montes, serras, e a mim chegou por modo misterioso. (p. 27)

Na segunda parte, o eu lírico abandona o seu discurso e insere uma narração poética na qual remonta às origens da droga mágica. Um velho pajé, casado, porém "sentindo-se incapaz/ de bem cumprir a lei do matrimônio" (p. 28), invoca o demônio e “co'os manitós falando em uma cova" (p. 28), através de um pacto, compõe o elixir afrodisíaco. A eficácia do mesmo logo se faz sentir:

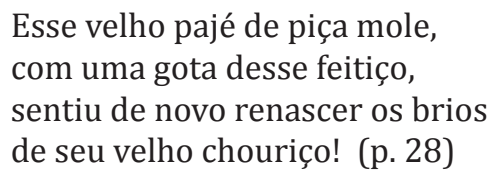

Para dar foro de autenticidade "nacionalista" à sua composição e, sem dúvida, para torná-la também jocosa -, Bernardo Guimarães se apropria do legado da geração romântica imediatamente anterior, fazendo uso de todo um contexto cultural indígena. 0 autor incorpora no seu trabalho poético, via intertextualidade, além do vocabulário, um dos esquemas rítmicos caros a Gonçalves Dias em sua linha indianista. Esse último, em várias composições de sua linha acima mencionada fez uso da redondilha menor com os acentos na segunda e na quinta sílabas poéticas,o que é ressaltado pela fortuna crítica. Para citar apenas um exemplo, comparem-se os textos a seguir:

\footnotetext{
Se as matas estrujo

Co'os sons do Boré, Mil arcos se encurvam, Mil setas lá voam, Mil gritos reboam, Mil homens de pé
} 
"O canto do guerreiro"

(DIAS, [s. d.], p.20-21)

\author{
E ao som das inúbias \\ ao som do boré, \\ na taba ou na brenha, \\ deitado ou de pé, \\ no macho ou na fêmea, \\ de noite ou de dia, \\ fodendo se via \\ o velho pajé! (p. 30)
}

Bernardo Guimarães também se utiliza, como já fora feito igualmente por Gonçalves Dias, da "polifonia"3, para usar um termo caro a Mikhail Bakhtin, dando voz ao coletivo e ao próprio pajé, instituindo assim a democracia das vozes. Em que pese a citação extensa, ela é necessária para que se comprove o que foi mencionado:

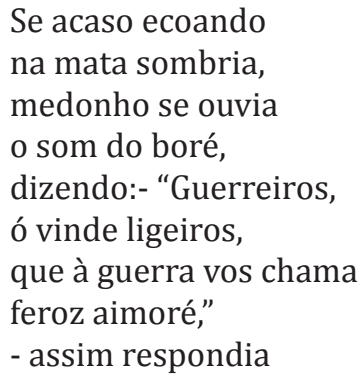

\footnotetext{
${ }^{3}$ Tem-se consciência da apropriação redutora que se faz em relação ao termo bakhtiniano, caso o poema for visto no seu todo. No entanto, as vozes que participam do diálogo poético parecem estar em pé de igualdade quando enunciadas no tempo pretérito, ou seja, quando da narração da história do pajé. Aí - e só aí - as vozes parecem ser, como queria Bakhtin, "plenivalentes" (Cf. BAKHTIN, Mikhail. Problemas da poética de Dostoiévski. Rio de Janeiro: Forense-Universitária, 1981. p. 2). Em oposição à guerra e à religiosidade, o pajé contrapõe o seu discurso da valoração do erótico. Contudo, o poema no seu todo tem, ressalte-se, a voz exclusiva e exclusivista do eu lírico: a mulher, para lembrar apenas um exemplo, embora "parceira", é "sem voz", aspectos já salientados por Luiz Costa Lima (1991, p. 249). Quanto ao criador, no caso, Bernardo Guimarães, a situação torna-se ainda mais complexa: ele invade, até certo ponto o discurso instituído, uma vez que sua voz é clandestina pela circulação restrita de sua obra. Era, no entanto, o que a época lhe oferecia como atitude para contaminar o discurso oficial.
} 


o velho pajé,
brandindo o caralho,
batendo co'o pé:
-"Mas neste trabalho,
dizei, minha gente,
quem é mais valente,
mais forte quem é?
Quem vibra o marzapo
com mais valentia?
Quem conas enfia
com tanta destreza?
Quem fura cabaços
com mais gentileza?" (p. 30)

Cumpre ressaltar o cunho parodístico do texto de Bernardo Guimarães no que tange ao conteúdo, pois, se no ritmo o teor é parafrástico, naquele a voz que institui o canto paralelo destrói a grandeza, a heroicidade do texto-matriz.

É o próprio Gonçalves Dias quem, em nota explicativa, observa que os pajés eram "anacoretas austeros, que habitavam cavernas hediondas nas quais sob pena de morte, não penetravam profanos", acrescentando que viviam "rígida e sobriamente", eram "objeto de culto e respeito para todos", sendo da mesma forma "os dominadores dos chefes" (DIAS, [s. d.], p. 112).

Bernardo Guimarães desconstrói, assim, com a sua criação, o caráter de sacralidade atribuído aos pajés, desviando-o, através do erotismo, para um processo que ressalta a humanização da figura do feiticeiro. Sem dúvida nenhuma, um pajé preocupado com a sua potência viril está longe da valorização e do poder transcendente a ele atribuído. Dessa forma, Bernardo Guimarães, via intertexto, corrói, revelando o seu desgaste, um dos mitos românticos, o da idealização do indígena.

Através de uma escritura transgressora pelo excesso, que na economia da obra se faz principalmente por intermédio do vocabulário, Bernardo Guimarães desbanca igualmente o cânone literário instituído.

Na terceira e última parte, com a morte do pajé, o eu lírico herda 
o elixir e, novamente dirigindo-se ao pênis, incentiva-o. Prepondera, nesse momento, o modo imperativo: "exulta, exulta", "eleva a fronte altiva", "sacode hoje os badalos", "alimpa esse bolor, lava essa cara" (p. 33). Em sua alegria, o eu lírico igualmente conclama as mulheres para as aventuras sexuais, perpassando nesse convite um cunho orgiástico:

\author{
Vinde, ó putas e donzelas, \\ vinde abrir as vossas pernas \\ ao meu tremendo marzapo, \\ que a todas, feias ou belas, \\ com caralhadas eternas \\ porei as cricas em trapos... \\ Graças ao santo elixir \\ que herdei do pajé bandalho, \\ vai hoje ficar em pé \\ o meu cansado caralho! (p. 34)
}

As qualidades do elixir são louvadas ao extremo pelo eu lírico, que enfatiza o fato de apenas uma gota dele conter "quinze dias de tesão" (p. 35), podendo "...um cento de fêmeas/ foder de fio a pavio,/ sem nunca sentir cansaço..." (p. 35). Mas, note-se que, ao lado do emprego do modo imperativo, o eu lírico faz uso também do subjuntivo, que é o modo da possibilidade, da incerteza. Conjugados, resultam numa atitude psicológica dúbia, em que ele, temeroso e duvidando - passe o termo - inconscientemente, projeta as possíveis glórias que advirão se o afrodisíaco for realmente eficaz. Confirmese com a última estrofe do poema:

Sim, faze que este caralho, por tua santa influência, a todos vença em potência, e, com gloriosos abonos, seja logo proclamado vencedor de cem mil conos... E seja em todas as rodas d'hoje em diante respeitado como herói de cem mil fodas, 
por seus heroicos trabalhos,

eleito - rei dos caralhos! (p. 37)

De maneira sagaz, Bernardo Guimarães encerra o poema sem que o eu lírico relate o seu desempenho concreto e a eficácia real (ou não) do "santo elixir". Esse vazio textual, permite ao leitor colocar o remédio em questionamento, do qual resulta uma ambiguidade que só faz aumentar o caráter literário da obra.

\section{"A origem do mênstruo"}

Como já se afirmou, o poema "A origem do mênstruo" foi lançado também em 1875 em conjunto com o "Elixir do pajé", sendo, entretanto, omitido o seu nome no título. Tal atitude não deixa de ser intrigante, geradora que é de um questionamento acerca de tal ausência.

O emprego da palavra "mênstruo" é, sem dúvida, a causa dessa supressão, o que pode ser constatado até em um crítico recente: Antonio Candido declara ser um "poema de título irreproduzível", acrescentando que "o sangue rutila na composição esmeradamente clássica, infiltrando estranhas manifestações de perversidade" (1975, p. 175).

A propósito, Georges Bataille, ao se referir ao sangue menstrual, considera-o redutível a um interdito maior: "o horror informe à violência”, que o ser humano associa à sexualidade. A menstruação seria, assim, um "signo da violência interna", ou mais especificamente, como algo impuro, como um dos "efeitos da violência" (1987, p. 50). A linguagem que não ostenta o seu referente, que se nega a reproduzi-lo num primeiro plano, seria, deduz-se, uma forma de se afastar da violência, carreada pela própria enunciação linguística. Em contrapartida, a sua nomeação no interior da obra, pode ser lida como uma violação que se exerce, sobretudo, na própria linguagem.

Por outro lado, "A origem do mênstruo" traz, parenteticamente, uma elucidação que, pelo contexto, se torna risível, pois intenta dar foros de verdade a uma criação do imaginário: “(De uma fábula 
inédita de Ovídio, achada nas escavações de Pompeia e vertida em vulgar por Simão de Nuntua)" (p. 41).

0 poema apresenta uma estrutura mais rígida que o "Elixir do pajé". Todas as estrofes são constituídas de quartetos, nos quais se alternam versos decassílabos e hexassílabos, apenas os últimos apresentando rimas. De cunho narrativo como o próprio título sugere, relata como se originou a menstruação. A escritura erótica transgressora já se faz presente nas primeiras estrofes e será utilizada ao longo de todo o poema:

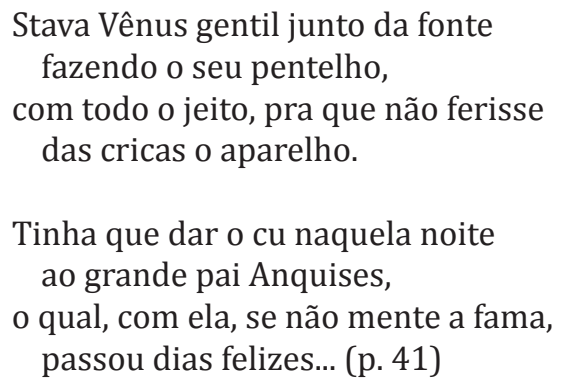

A ninfa Galateia, que por ali passava, vendo a posição da Vênus, toda agachada, "julgou que ela cagava..." e por ser "travessa e petulante" e por ter o "gênio mau" (p. 42), arremessa uma pedra que atinge a deusa:

Vênus se assusta. A branca mão mimosa se agita alvoroçada, e no cono lhe prega (oh! caso horrendo!) tremenda navalhada.

Da nacarada cona, em sutil fio, corre purpúrea veia, e o nobre sangue do divino cono as águas purpureia... (p. 42)

Momentaneamente, o narrador abandona o processo do contar 
e, como já fizera no terceiro verso da primeira das estrofes acima, introduz, de forma parentética e avaliativa, a sua voz no contexto narrativo, ressoando, de certa forma, o "Elixir do pajé":

(É fama que quem bebe dessas águas

jamais perde a tesão

e é capaz de foder noites e dias, até no cu de um cão!) (p. 43)

A deusa diz um palavrão e Galateia solta uma risada. A ninfa, contudo, intui a gravidade de sua ação e preocupa-se:

-"Estou perdida!"- trêmula murmura

a pobre Galateia,

vendo o sangue correr do róseo cono

da poderosa deia... (p. 43)

Vênus, por seu turno, extremamente irritada, invoca deuses e heróis, entre eles, Júpiter, Marte, Adônis e Aquiles para que a vinguem. Dirigindo-se a Galateia, lança-lhe a maldição de não encontrar ninguém que a deseje. Novamente, há certa ressonância de Gonçalves Dias, no anátema lançado pelo pai ao filho em "I-Juca Pirama":
Ó ninfa, o teu cono sempre atormente perpétuas comichões, e não aches jamais quem nele queira vazar os seus colhões...

Em negra podridão imundos vermes roam-te sempre a crica, e à vista dela sinta-se banzeira a mais valente pica!

De eterno esquentamento flagelada, verta fétidos jorros, que causem tédio e nojo a todo mundo, até mesmo aos cachorros!" (p. 46-47) 
Jove escuta os clamores da deusa e, dirigindo-se a Cupido "que em pívia (...)/ Comia nesse instante...", ordena-lhe que “...de pronto, acuda/ à puta que o pariu..." (p. 47). 0 emprego da última expressão revela-se plena de humor, uma vez que faz retornar o sentido do clichê exclamativo, geralmente associado à discordância do emissor, à sua significação literal. Como se sabe, a geradora de Cupido não era nada comedida nas suas aventuras sexuais...

O filho desce do Olimpo e recolhe a mãe que se esvai em sangue, retornando à morada dos deuses que "... reunida,/ a espera consternada!" (p. 49). Os deuses masculinos a ajudam, enquanto Juno e Palas "lembrando o antigo pleito" (p. 50), isto é, recordando a disputa que tiveram com a deusa para ver quem era a mais bela, deliciam-se com o seu infortúnio.

Por fim, Jove lavra um decreto em que aprova todas as imprecações de Vênus e acrescenta:

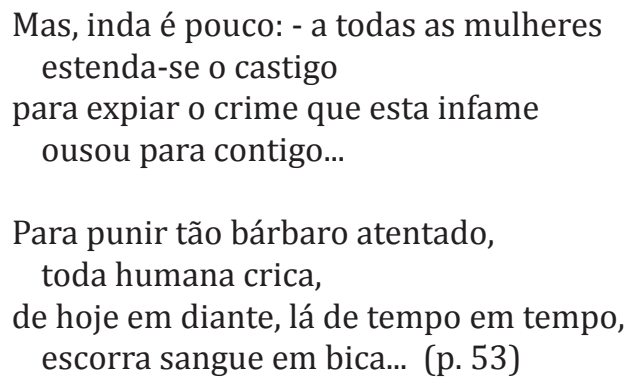

Os deuses todos concordam com o castigo imposto pelo senhor do Olimpo, e a última estrofe torna-se mais deslocadora, uma vez que Bernardo Guimarães incorpora à enunciação dos deuses pagãos a palavra "Amém", vocábulo sacralizado no espaço religioso do universo judaico-cristão:

Amém! Amém! com voz atroadora os deuses todos urram!

E os ecos das olímpicas abóbadas, Amém! Amém! sussurram... (p. 53) 
Novamente embasando-se em Mikhail Bakhtin, Duda Machado analisa o poema sob o viés "da poética da carnavalização e da sátira menipeia" (1992, p.18), afirmando que Bernardo Guimarães "constrói um poema narrativo de extrema inventividade para dessacralizar e rebaixar o universo clássico dos motivos mitológicos, virando o Olimpo pelo avesso" (1992, p.17).

Seja destruindo o tema romântico da natureza acolhedora, seja questionando a virilidade masculina, ou, ainda, subvertendo o mito clássico, Bernardo Guimarães inscreve-se, no sistema literário brasileiro, como um transgressor da lei, até mesmo quando a reforça ao fazer circular clandestinamente alguns de seus poemas, pois, conforme bem elucida Georges Bataille, "a transgressão não é a negação do interdito, mas o ultrapassa e o completa” (1987, p.59).

Em Bernardo Guimarães é pela via do riso e da intertextualidade que se invade o cânone instituído e se realiza a sua consequente transgressão literária. Para além das virgens inefáveis e inatingíveis, dos mancebos heroicos e respeitadores, da religiosidade impecável e sombria, reinscreve-se o humano, o terrenal, o humor e o erótico como formas desordenadoras de um idealismo tanto exacerbado quanto já desgastado pelo romantismo brasileiro de primeira hora.

\section{REFERÊNCIAS BIBLIOGRÁFICAS}

BAKHTIN, M. Problemas da poética de Dostoiévski. Rio de Janeiro: Forense-Universitária, 1981.

BATAILLE, G. 0 erotismo. Porto Alegre: L\&PM, 1987.

BRANCO, L. C. 0 que é erotismo. 2. ed. São Paulo: Brasiliense, 1987.

CAMPOS, H. de. Poética sincrônica. In: A arte no horizonte do provável. 4. ed. São Paulo: Perspectiva, 1977. 
CANDIDO, A. Bernardo Guimarães, poeta da natureza. In: Formação da literatura brasileira: momentos decisivos. 5 . ed. Belo Horizonte: Itatiaia; São Paulo: Universidade de São Paulo, 1975. v. 2.

DIAS, G. Poemas de Gonçalves Dias. Rio de Janeiro: Tecnoprint, [s.d.].

GUIMARÃES, B. Elixir do pajé: A origem do mênstruo, A orgia dos duendes. Introdução de Romério Rômulo. Sabará (MG): Dubolso, 1988.

LIMA, L. C. Pensando nos trópicos. Rio de Janeiro: Rocco, 1991.

MACHADO, D. Poesia erótica e satírica: Bernardo Guimarães. Rio de Janeiro: Imago, 1992.

PERKOSKI, N. A escritura erótica no sistema literário brasileiro. 1996. 312 f. Tese (Programa de Pós-Graduação em Letras) - Pontifícia Universidade Católica do Rio Grande do Sul, Porto Alegre, 1996. 
190 - Revista Texto Poético | ISSN: 1808-5385 | Vol. 16 (1ºm-2014) | p. 169-190 